\title{
Emerging stronger?
}

\section{Assessing the outcomes of Habitat for Humanity's housing reconstruction programmes following the Indian Ocean Tsunami}

First author, affiliation: Victoria Maynard, Centre for Urban Sustainability and Resilience, University College London, and Habitat for Humanity Great Britain

Email: v.maynard.12@ucl.ac.uk

Second author, affiliation: Priti Parikh, University College London

Third author, affiliation: Dan Simpson, Habitat for Humanity International

Fourth author, affiliation: Jo da Silva, Arup International Development 


\section{Introduction}

Habitat for Humanity (HFH) built, rehabilitated or repaired homes for 25,000 families in Indonesia, Thailand, Sri Lanka and India in the five years following the Indian Ocean tsunami in 2004. This represents $7 \%$ of the total housing need of approximately 440,000 houses across the four countries (International Recovery Platform 2011). In response to one of the worst natural disasters in recent history HFH's approach emphasised:

- community-based strategies involving local people in decision making;

- encouraging families to rebuild their homes in-situ;

- a preference for a simple core house design that could be extended later;

- working with partners to reach more families;

- a focus on the poorest and most vulnerable families;

- mobilizing HFH's network of volunteers to assist; and

- assisting others in need in neighbouring areas who had not been directly affected by the tsunami and those likely to be affected by future natural disasters (Habitat for Humanity 2009).

In 2009 HFH commissioned Arup International Development (Arup ID) to carry out an assessment of its housing reconstruction programmes in India, Sri Lanka, Thailand and Indonesia after the tsunami based on their previous experience in postdisaster reconstruction (Da Silva 2010; Batchelor \& da Silva 2010). The purpose of this assessment was to investigate the extent to which HFH's housing reconstruction programmes had contributed to the development of sustainable communities and livelihoods (Chambers \& Conway 1992; DFID 1999); namely their contribution to increased human, social, physical, economic and environmental assets as well as more enabling institutional structures and processes.

This paper describes the methodology for undertaking the assessment. It then describes common strengths and weaknesses of the programmes evaluated in terms of houses and settlements as 'products' (or outputs), as well as the process of housing construction through engagement with households, communities, governments and 
other actors. In conclusion the authors reflect on the findings from the assessment, highlight key strengths and recommend areas for improvement in future programmes.

\section{Methodology}

This research was completed between November 2009 and March 2010; roughly five years after the disaster and less than three years after the completion of construction. The assessment was based on programme documentation provided by country offices and one week of fieldwork per country which included: key informant interviews; workshops with HFH personnel; visual observation of four or five communities; participatory workshops using standard Participatory Rapid Appraisal (PRA) techniques; and completion of questionnaires by 30 households. This provided a range of quantitative and qualitative data on which to base the assessment.

The data was analysed using the ASPIRE tool Arup ID had developed previously with Engineers Against Poverty (2009a). This tool provides a holistic appraisal framework which generates a qualitative assessment based on 96 indicators under four key dimensions. Three of ASPIRE's dimensions (society, environment and economics) incorporate the human, social, natural and financial assets from DFID's Sustainable Livelihoods Framework (DFID 1999) 'assuming that the fifth dimension of physical assets is the project itself' (Arup \& Engineers against Poverty 2009b). The fourth key dimension (institutions) assesses the project's relationship with and contribution to the development of enabling institutions, organisations, policies and legislation - the 'transforming structures and processes' aspects of DFID's Sustainable Livelihoods approach.

Arup ID one assessment for each country (Arup 2010a; Arup 2010b; Arup 2010c; Arup 2010d) and a fifth assessment covering all four countries (Arup 2010e). This enabled comparison of both the outcomes of the four programmes and how these varied as a result of different approaches and contextual issues. The results of Arup ID's assessments fed into HFH's broader organisational and learning review of their tsunami-response programme in 2009-10. In writing this paper the authors have also returned to the original data to review the key findings and broader themes emerging 
from the assessment. Thus the findings presented below both reinforce the initial assessment and add additional insights where these have been identified through the review process.

\section{Housing as a product}

\subsection{Site selection and settlement planning}

All of HFH's programmes after the tsunami had a strong focus on in-situ housing reconstruction which meant that households maintained access to existing social networks, employment opportunities and social infrastructure such as schools, health centres, places of worship, community meeting places etc. (where these had not been destroyed by the tsunami). However, responsibility for reinstating social infrastructure typically resided with government or other humanitarian organisations so this produced varying levels of service.

While in-situ reconstruction had many benefits to communities it also meant that they remained in coastal locations vulnerable to flooding, storm surges and cyclones. Although HFH engaged with the whole community as part of the process of housing reconstruction its approach to the built environment focused on the reconstruction of individual houses: for example HFH's programmes sometimes included the provision of community facilities (such as schools) but rarely included settlement level infrastructure such as roads or storm water drainage. The assessment found that lack of consideration to hazard assessment, settlement planning and infrastructure at a settlement level was a significant contributing factor to continued levels of risk within the communities. Households interviewed in all four countries continued to feel at risk from flooding (this varied from $28 \%$ in Thailand to $79 \%$ in Sri Lanka) with several households in Indonesia reporting that they had already experienced flooding within their new houses one or more times a year.

Despite the focus on in-situ reconstruction, resettlement programmes did occur in all four countries. This was particularly rare in Thailand and Indonesia but a necessary reality in India and Sri Lanka after the governments introduced 'buffer zones' minimum distances from the coastline within which houses and communities could 
not be reinstated. Relocated communities were less vulnerable to natural hazards; with community members stating that they felt safer as they were at a greater distance from the sea. However, relocated communities in India and Sri Lanka reported reduced access to education and employment opportunities as well as less community cohesion.

Figure 1: Flooded houses in Indonesia at the time of the assessment

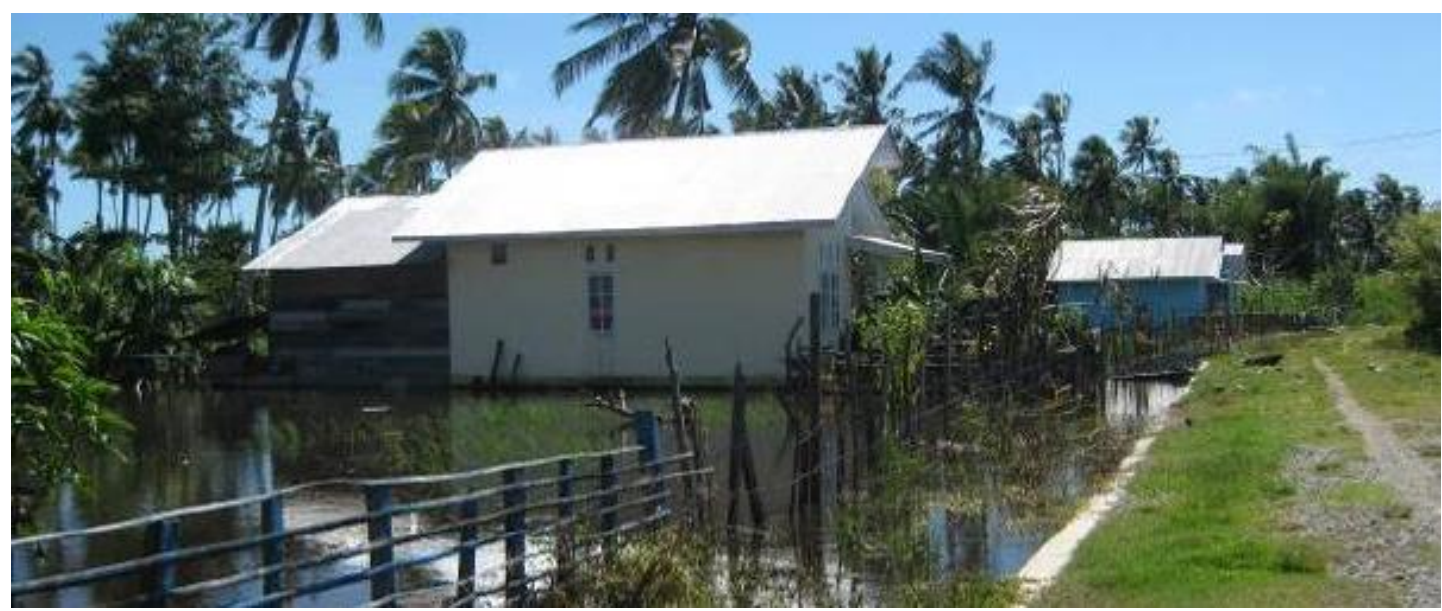

HFH worked pragmatically to resolve land tenure issues in all four countries, but different policy environments meant this had mixed levels of success. In Indonesia HFH supported communities in community-driven tenure adjudication through the government Reconstruction of Aceh Land Administration System (RALAS) programme, while (at the time of the assessment) land tenure for relocation communities in India and Sri Lanka was yet to be clearly resolved. HFH's tsunamiresponse programme in Thailand worked with Muslim and Morgan (nomadic seabased) communities - both of which are minority groups in Thailand. In several communities where land ownership was unclear HFH Thailand worked with local government to gain security of tenure for households before beginning construction of houses; enabling them to build permanent housing and invest in their homes.

\subsection{House design and construction}

HFH programmes in all four countries provided a simple single-storey core home which could later be extended (see Figure 2). Core homes in Sri Lanka and India were smaller (around $30 \mathrm{~m}^{2}$ ) and contained two rooms (a living room and a bedroom) 
while core homes in Thailand and Indonesia were larger $\left(40-45 \mathrm{~m}^{2}\right)$ and typically included a living room with one or two bedrooms. Households interviewed were generally satisfied with the size of their core homes, but HFH had not included space or facilities for cooking; leaving more than $50 \%$ of households dissatisfied with this aspect of the design. In India, Indonesia and Thailand 45-60\% of households had already extended their houses at the time of the assessment (only $28 \%$ in Sri Lanka) while more than $60 \%$ of households planned to do so in the future. In India and Sri Lanka many households had changed their room layouts and converted the smaller rooms into pujas (worship areas) or kitchens, while in Indonesia the majority of extensions were to accommodate a large kitchen suitable for entertaining guests. While this provides positive evidence that HFH's core home design enabled people to easily adapt or extend their houses, so many extensions or alterations being undertaken for the same purpose, less than three years after completion of the core home, may also indicate that families were making these changes out of necessity because of limitations in the original core home design.

Figure 2: Typical core home designs

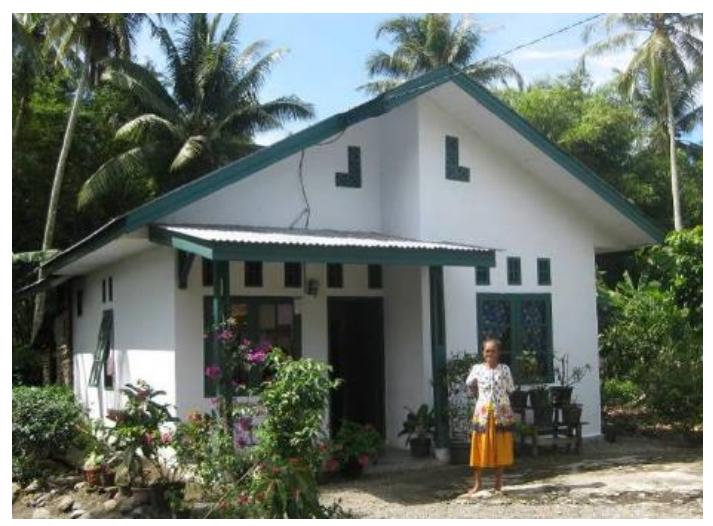

Indonesia

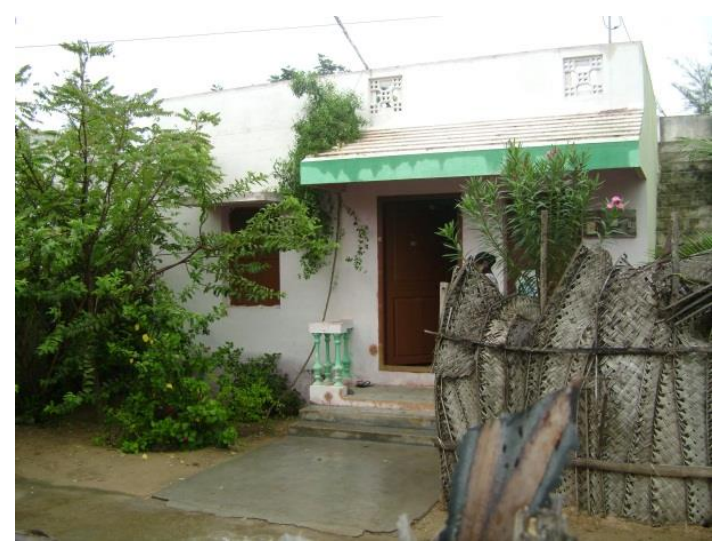

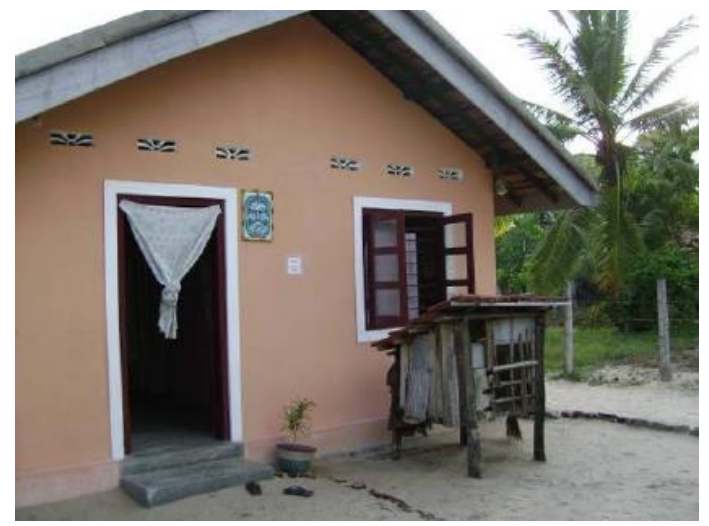

Sri Lanka

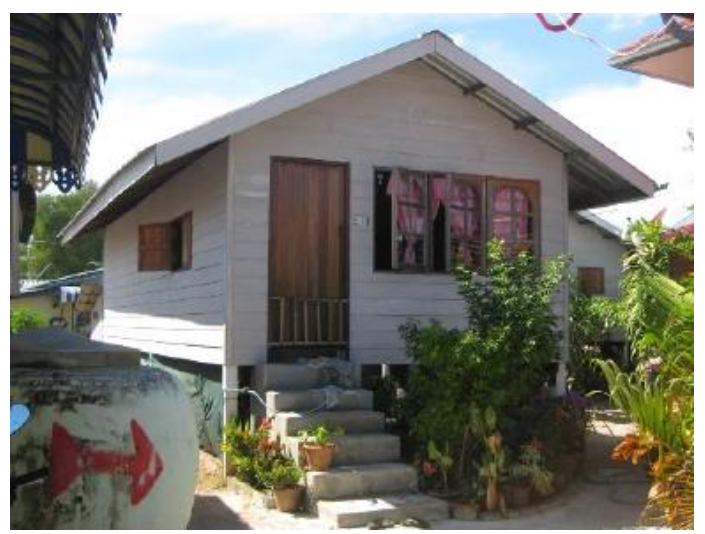


Core homes were typically masonry construction with a flat (India) or pitched roof with tiles or metal sheeting. HFH Indonesia introduced concrete block construction (a new technology in Aceh) and established its own block production facility. This significantly increased the speed of construction and reduced both cost and local environmental impact (as local timber was not used for burning bricks). Although communities initially did not believe that concrete blocks were suitable for housing, HFH staff reported that once the blocks had been proven they were well accepted. However, despite concrete blocks continuing to be manufactured by local suppliers after the completion of the programme, the majority of extensions had been completed in timber or bricks and where extensions had been completed in masonry they did not include the key seismic details included in HFH's core home designs (see Figure 3). HFH's core home designs in Thailand were based on small improvements to traditional housing typologies; for example where people had traditionally lived in timber houses on stilts HFH introduced concrete stilts and concrete board cladding (which can be used like timber). Thus, while the overall quality of core homes provided by HFH in Thailand was less than in other countries (for example concrete board cladding is less robust than masonry) the construction materials and techniques were closer to the vernacular and families found it easier to maintain and adapt their houses using similar techniques. 
Figure 3: HFH's core home design (far right) in one community in Indonesia which incorporates the re-use of a timber transitional shelter as a kitchen (right) and later extensions using a combination of timber and other materials (centre and left).

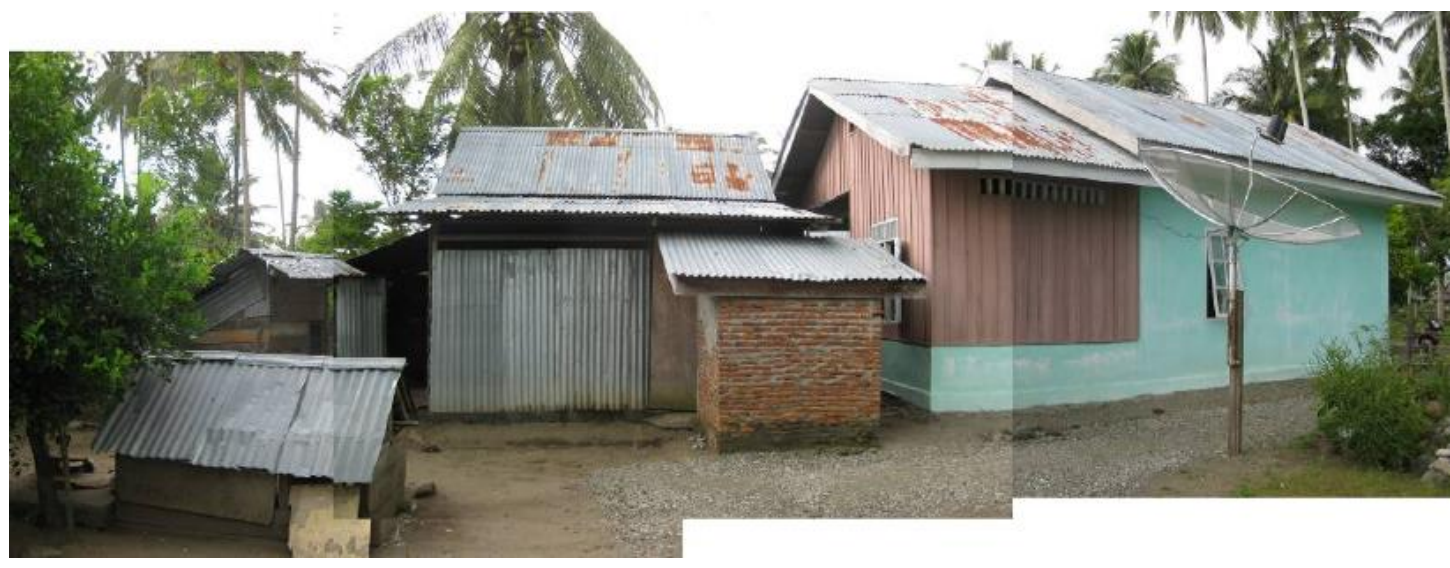

Although physical disaster risk reduction measures at a settlement level were not typically part of HFH's tsunami-response programme, house by house hazard assessment and mitigation was undertaken. Typical disaster risk reduction aspects of HFH core homes included: rebuilding houses in different locations within the settlement because of unsuitable soil conditions for foundations (Indonesia); raising the ground floor slab of houses in flood prone areas (Indonesia, India, Sri Lanka); building houses on stilts (Thailand); ensuring robust earthquake resistant design and construction (Indonesia) and incorporating cyclone resistant features such as concrete roofs (India and Sri Lanka).

In hot, humid climates minimising internal temperatures and ensuring adequate ventilation make a significant contribution to individual health and well-being. Across all four countries more than $60 \%$ of the households interviewed felt comfortable with the temperature inside their home but there were significant variations in house designs and levels of thermal comfort between countries. In Indonesia overhanging eaves provided some shading to windows and walls, a ventilated pitched roof with ceiling reduced heat transmission through the roof while ventilation bricks were provided above windows and doors in each room. Pitched roofs and ventilation bricks were also a feature of HFH's core home design in Sri Lanka and while ceilings were not included to reduce heat transmission HFH staff 
felt that sufficient ventilation was provided through gaps in the roof tiles. HFH's core homes in India typically had concrete walls and roofs with no insulation to reduce heat transmission into the house, limited shading of external windows or walls and little or no ventilation other than windows. In contrast the lightweight construction of HFH Thailand's core home - often raised on stilts - maximised the potential for ventilation through having several windows which either fully open or have glass louvres depending on the preference of the household.

\subsection{Access to services}

Communities in all four countries had high water tables and households typically sourced water from rivers or shallow wells. In general HFH did not include the provision of water supplies in their tsunami-response programme because these were typically provided by government or other NGOs. Notable exceptions are: Indonesia, where HFH provided water supply systems (either boreholes or water filtration) in six villages and established small committees to manage the systems and Thailand, where HFH partnered with another NGO to provide rainwater harvesting equipment (guttering and large ceramic pots) to some, but not all, households.

HFH provided toilets to each household assisted in India, Sri Lanka and Indonesia; often to families who had not previously had access to improved sanitation at a household level. In Thailand HFH's earlier projects did not include toilets as part of their core house design but these were included later projects and in the repayment programme many households had used their loan to build toilets and kitchen extensions onto their houses.

The provision of improved sanitation was particularly successful in Sri Lanka where septic tanks met national standards and can be emptied by the local government. HFH also worked with public health inspectors to promote hygiene awareness and $97 \%$ of households interviewed felt that their new facilities met their needs. In contrast, HFH India provided leach pits with the toilets in some houses and in areas with high water tables these posed a potential source of ground water contamination. The assessment also noted that in some communities only women used the toilets. In Indonesia water, sanitation and hygiene training was only provided in the six 
communities where $\mathrm{HFH}$ had provided water supply systems and this left many communities unaware of the importance of using their new toilets with some families not understanding how to maintain them or how to empty their septic tanks once full. Consequently $37 \%$ of families interviewed were no longer using the bathrooms for a variety of reasons including leaks, closeness of the toilet to the living area and their preference to continue using traditional practices.

While some of the sanitation challenges experienced in India and Indonesia were related to the physical design and construction of facilities they were primarily a result of programme design which did not adequately respond to communities' existing knowledge, attitudes, and practices. This highlights the importance of an integrated approach to water, sanitation and hygiene, with improvements in future programmes needed to ensure understanding at household level and a strategy for long-term operation and maintenance of the facilities provided.

In India, Indonesia and Thailand HFH worked with the government to provide electricity connections to all HFH families; in India and Thailand only a few households had not previously had electricity connections, but in Indonesia this had increased coverage from 60 to 100\% of the households interviewed. In Sri Lanka the number of households with electricity connections had decreased from $21 \%$ before the tsunami to only $10 \%$ after the HFH programme. HFH Sri Lanka struggled to find sites for relocation settlements with access to electricity and lack of clarity on land tenure for these communities further delayed the provision of electricity connections. In response to the challenge of providing mains grid electricity HFH Sri Lanka supported the use of solar technology. $48 \%$ of households interviewed understood and used solar energy for lighting and small appliances (compared to $31 \%$ before the tsunami). HFH Sri Lanka also introduced the use of solar cookers. However the evaluation noted that solar technology was not fully understood by communities and further support was required for it to be fully successful.

Although HFH's tsunami-response housing programme did not specifically target fuel consumption, 10-25\% of households interviewed in Indonesia, Thailand and India had stopped using wood or charcoal for cooking since the tsunami. The 
assessment did not directly investigate the reasons for this change in behaviour but households in India cited the new housing as an incentive to switch over to gas. This may also be the case in Indonesia and Thailand, as HFH 'homepartners' typically expressed significant pride in their new houses, but it may also be attributed to raised environmental awareness (as a result of HFH's gardening programmes), increased access to electricity (particularly in Indonesia) or improved living standards more generally as a result of HFH's programme or the activities of government or other NGOs. If attributable to the HFH housing programme this is potentially an important outcome as reduced use of wood or charcoal for cooking both reduces the use of local timber for fuel and improves indoor air quality, with long-term benefits to health.

While HFH's programmes did not include the construction of educational facilities (except in isolated cases) $60-90 \%$ of the households interviewed felt that HFH's programme had increased access to education and this was reinforced in the interviews with community leaders. Households cited various factors for this improvement including: increased disposable income to spend on uniforms/books (because of reduced spending on housing); better conditions for studying including private rooms for children and increased electric lighting; and increased motivation and a sense of well-being. This was a significant positive finding of the assessment, despite the fact that some of the relocation communities did not have schools located within the community.

\section{Housing as a Process}

\subsection{Community engagement}

HFH typically established a project management committee in each community which included beneficiaries, community representatives and local government officials. Households and community leaders in all four countries felt that all sections of the community were able to participate in the project, that beneficiary selection criteria had been transparent and equitable, and that there was little corruption throughout the process. However, $10-20 \%$ of households interviewed in 
Indonesia and Sri Lanka did not find the HFH process easy to understand. In Indonesia this was in communities where they spoke predominantly the local language of Acehnese, rather than Indonesian, and in Sri Lanka this was in migrant communities where the high mobility of individuals and families reduced effective community engagement.

In several instances HFH targeted their assistance on the most vulnerable groups such as Morgan communities (Thailand), remote, lower caste, or migrant communities (Sri Lanka) and households with disabled family members (India). Households and community leaders in all four countries emphasised that the HFH programme had increased community cohesion through integrating vulnerable groups into society (India), increasing community spirit through providing 'sweat equity' on each other's houses (Thailand) and bringing members of diverse religious groups to work together (Sri Lanka). In Indonesia, where the cash for work programmes of other agencies had sometimes reduced the tradition of gotong royong (community self-help) (Thorburn 2007), this had been maintained in the communities where HFH worked, with communities working together to construct roads to enable materials to be delivered, cleaning drains etc.

In theory HFH developed a standard core home design in each country to suit the local culture and climate and this was further adapted following consultation with specific communities or households. In practice more than $70 \%$ of households interviewed reported being consulted regarding the location and design of their house; but it's less clear if changes were made as a result of the consultation. Many households commented that changes were not allowed as HFH had a standard house design while Arup ID's evaluation of the programmes in India and Sri Lanka noted that they 'are primarily driven by donor objectives and government guidelines' Positive evidence of design changes made by $\mathrm{HFH}$ in response to household and community needs included adaptation of the core home design for the needs of fishing communities, households with a larger than average number of members, or those with disabled family members (India) and positioning of the toilet within the bathroom so that it was not orientated towards Mecca (Indonesia). However, the possible limitations of the core home design and challenges experienced by HFH 
introducing new construction materials and techniques, seismic detailing, sanitation and solar technologies suggest that the level of engagement might be considered 'consultation' over minor details, rather than real 'partnership' in decision-making (Arnstein 1969) which built upon local knowledge, skills, attitudes and practices to co-develop appropriate designs.

Very different approaches to community involvement in housing construction were taken across the four countries leading to diverse outcomes on the development of skills and employment opportunities:

- There was very little involvement of beneficiaries in construction in India (either through 'sweat equity' or as paid labourers) with the majority of construction being undertaken by national contractors or international volunteers. Although these fishing communities had not traditionally built their own houses, this was a missed opportunity for both short-term employment opportunities (while livelihoods were disrupted during recovery) and skills transfer to communities so that households could supervise paid labourers to maintain and extend their houses safely in the future. Very few households interviewed stated that the HFH programme had generated employment for communities or local suppliers at any point during or after the reconstruction process.

- In Sri Lanka, few households could contribute 'sweat equity' during construction because they could not afford to take time away from their work but $45 \%$ of households interviewed took part as paid unskilled labourers. Beneficiaries and community members also had significant involvement in the selection of material suppliers resulting in $38 \%$ of households interviewed feeling that the HFH programme had generated employment opportunities for local suppliers and $17 \%$ stating that it had provided continuing employment opportunities after the completion of the programme.

- Construction in Indonesia was undertaken by professional labourers, sometimes from as far afield as Medan or Java because of the shortage of skilled labour closer to hand. HFH encouraged communities to establish good relationships with their labourers and while the beneficiaries did not take part in construction directly they were responsible for monitoring the quality of materials and 
workmanship on their own home. This encouraged a high degree of ownership, but although HFH provided training for local supervisors (one per ten houses) the households interviewed felt that they had not had specific training on how to monitor the quality of construction. As a result, by the time of the evaluation, households had already started to extend their houses without incorporating the key features of seismic resistant design.

- HFH achieved the greatest involvement of communities in construction in Thailand. There both beneficiaries and other community members were involved in all aspects of construction and $24 \%$ of households interviewed also felt that it had benefited local suppliers. The use of 'sweat equity' and international volunteers supported rather than competed with local labourers (as local capacity was exceeded in the aftermath of the tsunami) and households reported that working with international volunteers was a positive experience. So much involvement of households and communities during construction had significant benefits for these communities. Many learnt new skills during the process and of the households interviewed $90 \%$ felt that they had the skills and tools required to repair and maintain their home (compared with 30-50\% in other countries). At the time of the assessment many households had begun supplementing their income through construction employment during the rainy season when they were unable to fish.

HFH did not typically provide specific livelihood support programmes but sometimes: encouraged NGOs providing livelihood support to work in $\mathrm{HFH}$ communities (Thailand); partnered with other NGOs to provide livelihood training, tools or access to credit (Sri Lanka and India); or developed their own small-scale livelihood support programmes (Sri Lanka). HFH's programmes in India, Sri Lanka and Indonesia often included the support of household or community gardening after the completion of the housing programme while some households in Indonesia had also used the opportunity of a new house to purchase land close to the road and invest in opening a small business or shop. Despite localised instances of livelihood support, and some short-term benefits during the reconstruction programme the longterm reliance on low paid employment, subject to seasonal or climatic disruption, remained a key concern of most communities visited in the assessment. Thus, while 
there were positive examples of livelihoods support to some communities through HFH's programmes, the lack of a systematic strategy to support livelihood development within these vulnerable coastal communities was a significant missed opportunity.

Figure 4: Some households in Indonesia had chosen to re-locate within their community so that they could set up a small shop or cafe near to the road.

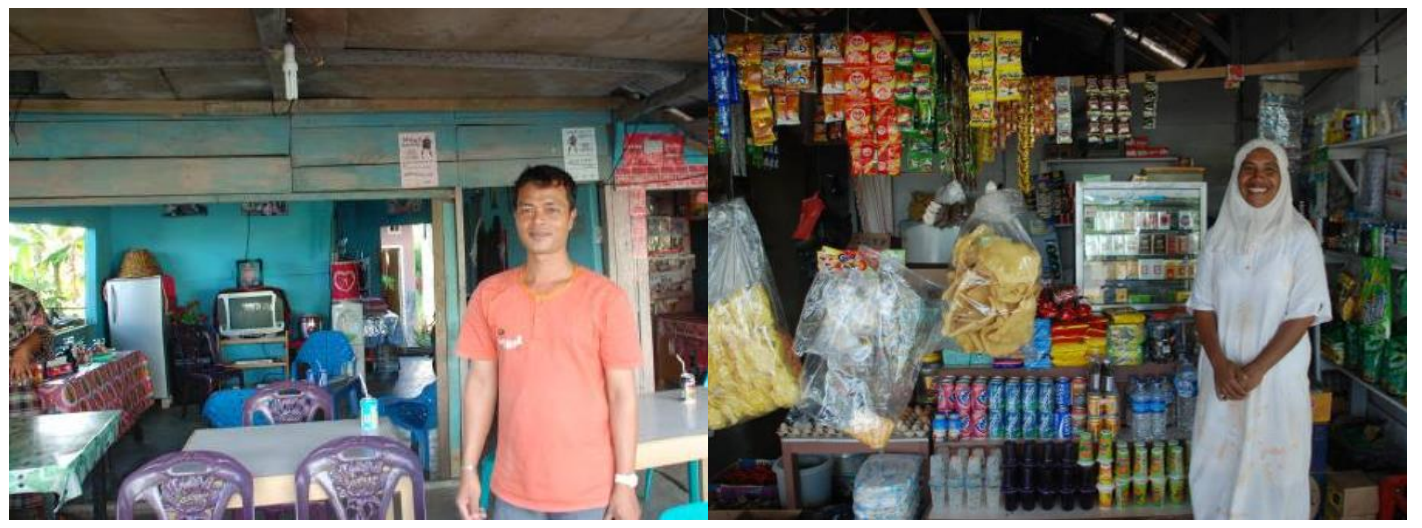

\subsection{Relationships with other actors}

A disaster on the scale of the tsunami required local and national governments to rapidly establish policy guidelines on eligibility criteria, reconstruction standards, land tenure etc. HFH managed the risk of undertaking reconstruction programmes in a rapidly changing policy environment through close liaison with local government officials, government reconstruction agencies and other humanitarian organisations. HFH's reconstruction programme in both Sri Lanka and Indonesia took place within complicated conflict or post-conflict situations. In both instances HFH worked sensitively with the government, military and police (in addition to communities and partner NGOs) to ensure that HFH were aware of the security situation and that HFH's programmes responded appropriately. In all countries the Head of the Village, or Village Committee (elected local government representatives), was heavily involved in HFH's programme. Local government officials at a municipal or district level often attended project start or completion ceremonies to show their support and sometimes provided public health training, approved material suppliers, designs or construction quality. 
HFH also worked closely with other NGOs working in the same communities, participated in knowledge exchange programmes, implemented programmes through partner NGOs (India) and partnered with specialist NGOs (for example in microcredit, provision of training or rainwater harvesting) when their skills were required (all countries). HFH's focus on working in partnership with communities, government and other NGOs meant that that a frequent finding from the assessment was that the project had improved linkages between the communities assisted and external actors.

In many cases HFH also established positive relationships with material suppliers, labourers and larger contractors; supporting wider economic recovery during the reconstruction process. This was particularly apparent in Indonesia where HFH: sourced materials locally whenever possible (with sand, aggregates and soil typically sourced from within the villages); ensured that all material suppliers were certified by local government (a potentially onerous requirement for small-scale suppliers, but HFH supported them through the process, which then made them eligible for other contracts once they had worked with HFH); supported capacity building in local suppliers (for example they developed a standard window design and then worked with local manufacturers to ensure that their products met the requirements of the specification).

\section{Conclusions}

Overall the assessment found that HFH's housing reconstruction programmes after the Indian Ocean tsunami had made a significant contribution to the development of sustainable communities and livelihoods. HFH's housing programme had replaced houses which had been destroyed in the tsunami, often to a higher standard and (in most cases) complete with access to services and social infrastructure. The provision of high quality core homes (physical assets) had reduced household vulnerability and increased the standard of living - with benefits to health and wellbeing (human assets) while HFH's participatory process had increased community cohesion (social assets). HFH's programme had also contributed to the development of positive relationships between communities and a range of external actors (institutional 
structures and processes) as well as supporting environmental and economic recovery (natural and financial assets) to a lesser extent.

The following sections sumarise both the strengths of HFH's tsunami-response programme and suggest areas for improvement in future programmes where small changes in programme design or implementation (at limited additional cost) could increase the long term impact of its work.

\subsection{Site selection and settlement planning}

HFH's focus on in-situ reconstruction meant that households had maintained their access to existing social networks, employment opportunities and social infrastructure (social, economic and physical assets). The physical assets of relocated communities were less vulnerable to natural hazards but households reported reduced access to education and employment opportunities as well as less community cohesion. This highlights that if relocation has to occur after a disaster it must be viewed holistically; with sufficient infrastructure provided and adequate support for community and livelihood development. A key area for improvement in HFH's future housing programmes is to more broadly incorporate community-wide hazard assessment and settlement planning into their community engagement process (preferably linked to wider government planning policies) and include disaster risk reduction infrastructure and activities at a settlement level.

\subsection{House design and construction}

HFH's policy to provide a simple core home that could later be extended enabled HFH to rapidly provide large numbers of permanent houses. The design of HFH's core home enabled people to easily adapt or extend their houses, but the fact that many households had made similar changes to their houses soon after completion, may also indicate the limitations of the original core home design. HFH's commitment to negotiating tenure security for each household was a significant benefit of the HFH programme, as was the incorporation of household-level hazard assessment and mitigation. However, greater emphasis could have been placed on climatically appropriate design. In several instances HFH introduced new 
construction materials or techniques, and while these examples show the organisation striving to innovate, this assessment found that these were easiest for households and labourers to understand and replicate themselves when they were incremental improvements on existing techniques.

\subsection{Access to services}

Water supplies were typically reinstated by other actors but HFH provided toilets for each household. While the provision of toilets was a positive aspect of HFH's programme, many families had not previously had access to improved sanitation and did not understand the importance of using their new toilets or know how to maintain them in the future. This highlights the importance of an integrated approach to water, sanitation and hygiene, with improvements in future programmes needed to ensure understanding at household level and a strategy for operation and maintenance of the facilities provided. Similar challenges with household understanding, acceptance and maintenance of new technologies were experienced where HFH introduced solar technologies to communities without access to mains grid electricity. HFH's programme also resulted in indirect benefits such as improved levels education as result of greater disposable income, private areas for children to study with electric lighting and increased motivation and well-being. The programme may have also contributed to decreased use of timber and charcoal as fuel; both reducing the use of local timber for fuel and improving indoor air quality, with long-term benefits to health.

\subsection{Community engagement}

HFH's community engagement process had significant benefits in terms of increased community cohesion (social assets). However, the limitations of the core home design and challenges experienced by HFH introducing new construction materials, seismic detailing, sanitation and solar technologies indicate that greater participation in decision-making (such as selection of construction materials and technologies) is required to ensure HFH's programmes meet the needs of the communities they intend to support. The assessment found that the more households and communities were involved during construction the greater the benefits in terms of livelihood 
diversification and equipping communities with the knowledge and skills to adequately maintain, adapt and extend their houses. It also highlighted that opportunities for employment generation during construction (in material supply or construction labour) were missed in many of HFH's programmes suggesting the need for a more holistic approach to livelihood support and diversification at household, community and sector level.

\subsection{Relationships with other actors}

HFH developed positive working relationships with a range of external actors in challenging situations - although partnerships with academic institutions were notably lacking. HFH's focus on working in partnership with communities, government and other NGOs meant that the project had improved linkages between communities' and external actors and developed a more supportive enabling environment. In many cases HFH also established positive relationships with material suppliers, labourers and larger contractors; supporting wider economic recovery during the reconstruction process and enabling HFH to scale-up their programmes through cost-sharing arrangements. While many of these partnerships were successful this assessment suggests that there is greater potential for partnerships in future reconstruction programmes to complement HFH's experience in housing construction with the specialist expertise of other actors to address some of the challenges raised in this assessment and maximise the impact of its work.

\section{Recommendations}

Every disaster response operation poses unique challenges as humanitarian organisations strive to support the unique needs of individuals, families and communities in different geographical, climatic, cultural and political contexts. Prescriptive recommendations for future programmes (such as 'use vernacular materials' or 'avoid relocation') are therefore less useful than approaches which can be adopted in any context. Based on this assessment the authors propose the following recommendations for HFH's future disaster-response operations: 
- the need for greater participation in decision-making throughout project design, construction, maintenance and replication to ensure that programmes really meet the needs of the families and communities they intend to serve;

- the importance of considering the long-term use of houses, infrastructure, construction materials, techniques or technologies from the outset. Will families be able to maintain, adapt, extend or replicate any new interventions themselves?

- the need for greater consideration of settlements in addition to houses to reduce risk and ensure that it is not just houses which are rebuilt but communities complete with spaces for education, healthcare, livelihoods and recreation.

- the importance of a holistic approach - maximising the contribution of all humanitarian interventions to social, economic, environmental, cultural and political recovery and resilience. 


\section{References}

Arnstein, S.R., 1969. A ladder of citizen participation. Journal of the American Institute of planners, 35(4), pp.216-224. Available at: http://www.tandfonline.com/doi/abs/10.1080/01944366908977225 [Accessed August 2, 2013].

Arup, 2010a. Habitat for Humanity's Tsunami-Response Shelter Programmes Sustainability Assessment: Country Report - India.

Arup, 2010b. Habitat for Humanity's Tsunami-Response Shelter Programmes Sustainability Assessment: Country Report - Indonesia.

Arup, 2010c. Habitat for Humanity's Tsunami-Response Shelter Programmes Sustainability Assessment: Country Report - Sri Lanka.

Arup, 2010d. Habitat for Humanity's Tsunami-Response Shelter Programmes Sustainability Assessment: Country Report Thailand.

Arup, 2010e. Habitat for Humanity's Tsunami-Response Shelter Programmes Sustainability Assessment: Summary Report.

Arup \& Engineers against Poverty, 2009a. A Sustainability Poverty and Infrastructure Routine for Evaluation (ASPIRE). Available at: http://www.oasys-software.com/products/environmental/aspire.html [Accessed April 20, 2013].

Arup \& Engineers against Poverty, 2009b. A Sustainability Poverty and Infrastructure Routine for Evaluation (ASPIRE): Research and Development. Available at: http://www.oasyssoftware.com/products/environmental/aspire.html [Accessed April 20, 2013].

Batchelor, V. \& Da Silva, J., 2010. Indonesia: Understanding agency policy in a national context. In M. Lyons \& T. Schilderman, eds. Building Back Better. Practical Action Publishing. Available at: http://practicalaction.org/buildingback-better-book [Accessed January 11, 2013]. 
Chambers, R. \& Conway, G., 1992. Sustainable rural livelihoods: practical concepts for the 21st century, Institute of Development Studies (UK). Available at: http://opendocs.ids.ac.uk/opendocs/handle/123456789/775 [Accessed August 2, 2013].

DFID, 1999. Sustainable Livelihoods Guidance Sheets. Available at: http://www.eldis.org/vfile/upload/1/document/0901/section2.pdf [Accessed January 11, 2013].

Habitat for Humanity, 2009. Emerging stronger: five years after the Indian Ocean Tsunami. Available at: http://www.habitat.org/asiapacific/Know_more/five_years_after_the_asiatsuna mi.aspx [Accessed April 20, 2013].

International Recovery Platform, 2011. Countries \& Disasters: Indian Ocean Tsunami, 2004. Available at: http://www.recoveryplatform.org/countries_and_disasters/disaster/15/indian_oc ean_tsunami_2004 [Accessed August 2, 2013].

Da Silva, J., 2010. Lessons from Aceh : key considerations in post-disaster reconstruction, Bourton-on-Dunsmore: Practical Action Publishing. Available at: http://www.arup.com/Publications/Lessons_from_Aceh.aspx [Accessed January 13, 2013].

Thorburn, C., 2007. The Acehnese Gampong Three Years On: Assessing Local Capacity and Reconstruction Assistance in Post-tsunami Aceh, Jakarta, Australian Agency for International Development (AusAID). www. indo. ausaid. gov. au/featurestories/acarpreport. pdf or www. conflictanddevelopment. org/data/doc/en/regCaseStudy/aceh/ACARP-reportlowRes. pdf. 